\title{
EMBRITTLEMENT \\ BY LIQUID METALS
}

W. ROSTOKER

Armôr Research Foundation

J. M. McCAUGHEY

Frankford Arsenal

H. MARKUS

Frankford Arsenal

REINHOLD PUBLISHING CORPORATION, NEW YORK CHAPMAN \& HALL, LTD., LONDON 